\title{
Pregnancy Outcome in Systemic Lupus Erythematosus (SLE) is Improving: Results from a Case Control Study and Literature Review
}

\author{
Sai Yan Yuen, Adriana Krizova, Janine M. Ouimet and Janet E. Pope* \\ Department of Medicine, The University of Western Ontario, London, ON, Canada
}

\begin{abstract}
Objectives: For women who suffer from systemic lupus erythematosus (SLE), pregnancy can be a concern, placing the mother and fetus at risk. Our objectives were to assess the risk of adverse pregnancy outcome, disease flares, fertility rate, and co-morbidities in SLE women compared to healthy controls. We also systematically reviewed the literature available on pregnancy outcome in SLE to compare our results to other published data. Our hypothesis was that pregnancy outcome in SLE is improving over time.

Methods: A case-control study comparing self-report of the above-mentioned parameters in SLE (N=108) vs healthy controls or patients with non-inflammatory musculoskeletal (MSK) disorders $(\mathrm{N}=134)$ was performed. Data were collected using a self-administered questionnaire. Proportions, means and odds ratios were calculated. We searched and quantified the literature on pregnancy outcome, lupus reactivation and fertility rate. Data were summarized and presented in mean $\%$ \pm SEM and median \% with interquartile range (IQR).

Results: Gynecological history, fertility rate and age at first pregnancy in SLE patients were comparable to controls. Eighteen percent of SLE patients reported a flare and 18\% reported an improvement of symptoms during pregnancy. Twenty-four percent of lupus patients had at least one preterm delivery $v s 5 \%$ in controls $(\mathrm{OR}=8.32, \mathrm{p}=0.0008)$, however other pregnancy outcomes (miscarriage, therapeutic abortion, stillbirth and neonatal death rate) did not differ between the groups. Thyroid problems were reported to be more likely in SLE patients $(p=0.02)$, but the prevalence of other co-morbidities was similar to controls. A literature review demonstrated that fertility was not affected in SLE patients. Lupus reactivations are common during pregnancy $(36.5 \% \pm$ SEM 3.3\%). Most agreed that SLE pregnancies had more fetal loss $(19.5 \% \pm$ SEM $1.6 \%)$ and preterm births $(25.5 \% \pm$ SEM $2.2 \%)$ when compared to the general population. Over time, the rate of SLE peripartum flares has improved $(\mathrm{p}=0.002)$ and the proportion of pregnancies resulting in live birth has increased $(p=0.024)$. The frequency of fetal death has not significantly changed. Our findings from the casecontrol study were, in general, consistent with the literature including the frequency of fetal death, neonatal death, live births and pregnancy rate.
\end{abstract}

Conclusion: Prematurity (25.5\% \pm SEM 2.2\%) and fetal death (19.5\% \pm SEM 1.6\%) in SLE pregnancy are still a concern. However, new strategies with respect to pregnancy timing and multidisciplinary care have improved maternal and fetal outcome in SLE.

Keywords: Pregnancy outcome, systemic lupus erythematosus (SLE), case-control.

\section{INTRODUCTION}

Systemic lupus erythematosus (SLE) is a serious multisystem disease affecting predominantly women of childbearing age. Fertility of SLE patients is usually comparable to the general population. There have been improved outcomes and survival in SLE. Likewise, adequate obstetrical care and perinatal management might ensure a better pregnancy outcome.

Historically, fetal and maternal well being of patients with SLE seemed to be compromised to the extent that the medical community recommended against pregnancy in SLE patients. It was difficult to assess whether superimposing pregnancy was detrimental as the clinical outcome of nonpregnant SLE patients was poor $[1,2]$. It seems that with better control of disease activity, pregnancy in SLE patients

*Address correspondence to this author at St. Joseph's Health Centre, 268 Grosvenor St., London, Ontario, N6A 4V2, Canada; Tel: 519-646-6332; Fax: 519-646-6334; E-mail: janet.pope@sjhc.london.on.ca is no longer an absolute contraindication. However, fetal and maternal complications still exist. Careful planning of pregnancy coupled with multidisciplinary monitoring and treatment substantially decreases the risks for the mother and the infant [3].

In this article we report a case-control study on pregnancy outcome, disease flares, fertility rate, and comorbidities comparing SLE patients vs healthy controls or patients with non-inflammatory musculoskeletal (MSK) disorders using a self-report questionnaire. We also compare our results to the current literature using a systematic quantitative approach. Our hypothesis was that pregnancy outcome is improving over time in SLE.

\section{MATERIALS AND METHODOLOGY}

A four-page questionnaire was sent to subjects with SLE and either healthy control subjects solicited from a newspaper advertisement or subjects who had non-inflammatory MSK disorders such as osteoarthritis, tendonitis and fibromyalgia. SLE patients and MSK patients were recruited 
from a single rheumatology clinic. This questionnaire contained 44 questions on socio-demographics and pregnancy history, and was approved by the Health Sciences Research Ethics Board of the University of Western Ontario, London, Ontario, Canada. All SLE patients met the American College of Rheumatology (ACR) criteria [4]. All subjects were blinded as to the hypothesis and were sent the questionnaire packages. Two follow-ups were sent to non-respondents.

Statistical analysis of the data was performed using JMP Statistical Discovery Software (SAS Institute, Cary, NC, USA). For each survey question, unanswered questions were excluded from the analyses. Group means, proportions, odds ratios (OR) and 95\% confidence intervals (CI) were calculated. Statistical significance was accepted at $\mathrm{p} \leq 0.05$. Analyses were redone after adjusting for age.

We also assessed laboratory results for antinuclear antibody (ANA), anti-double-stranded DNA (anti-dsDNA) antibodies and antiphospholipid antibodies (anticoagulant and anticardiolipin) in 36 patients from our lupus cohort. Standard assays were used for each type of antibody: immunofluorescent antinuclear antibody (ANA or FANA) test; ELISA for anti-dsDNA; lupus anticoagulant panel (activated partial thromboplastin time [aPTT] and modified Russell viper venom time [RVVT], platelet neutralization procedure [PNP] or kaolin clotting time [KCT], etc., as appropriate); and ELISA for anticardiolipin antibodies.

A review of the literature on pregnancy outcome in SLE was performed. Original articles on fertility rate, lupus flares during pregnancy, prematurity and fetal losses were selected. The search was conducted using the Pubmed database available at http://www.ncbi.nlm.nih.gov/entrez/query.fcgi?DB= pubmed. Terms used (in various combinations) were: systemic lupus erythematosus, pregnancy outcome, lupus pregnancy, fertility rate, prematurity, preterm delivery, fetal loss, fetal wastage (referred to as fetal death in this paper), fetal outcome, spontaneous abortions, miscarriage, intrauterine growth restriction, lupus flares, lupus nephritis. Due to the vast amount of literature available, some older and smaller studies were not included. Data reported from each article on pregnancy outcome, including fertility, parity, elective abortions, miscarriages, fetal loss, neonatal death, preterm or full birth rates and lupus flares were recorded. We calculated the mean $\% \pm$ SEM and median $\%$ with interquartile range (IQR) for each subject. We then classified these articles into 3 subgroups according to their publication date to assess temporal trends. Findings were summarized and compared to those obtained from our case-control study.

\section{RESULTS}

The response rate was $72 \%$ for SLE subjects and $69 \%$ for controls. The mean age of SLE subjects was $42 \pm$ SEM 1 years vs $38 \pm$ SEM 1 years for controls. Controls were more likely to continue their education above high school $(\mathrm{p}=$ 0.0001 ), and lupus patients were more likely to be homemakers $(p=0.01)$. In terms of marital status, there were no differences between the groups. All data are summarized in Table 1.

Eighty-three patients $(77 \%)$ in the SLE group ( $\mathrm{N}=108)$ had at least one pregnancy vs $93(69 \%)$ in the control group $(\mathrm{N}=134)$. Sixty-seven (> 60\%) SLE patients were pregnant prior to SLE diagnosis. Twenty-six of 83 SLE-women (31\%) had at least one miscarriage. Pregnancy was associated with a self-reported SLE flare in $18 \%$ of patients; however, $18 \%$ of patients also reported improvement. The number of pregnancies per woman was similar between the groups $(2.3 \pm$ 0.2 for SLE and $1.8 \pm 0.1$ for controls; $p=0.17)$. SLE patients and controls had a similar age of first pregnancy. Twenty-four percent of lupus patients had at least one preterm delivery vs $5 \%$ in controls $(\mathrm{OR}=8.32, \mathrm{p}=0.0008)$, but the pregnancy outcome was otherwise comparable (such as miscarriages, perinatal mortality). Thyroid problems (mainly hypothyroidism) were reported more in lupus patients $(21 \%$ vs $10 \%, \mathrm{p}=0.02)$, but the frequency of other co-morbidities was similar to controls, such as hypertension (13\% vs $21 \%$, p $=0.1)$ and diabetes mellitus $(2 \%$ vs $4 \%, \mathrm{p}=0.27)$. SLE patients were more likely to smoke during pregnancy (42\% vs $24 \%, \mathrm{OR}=2.35, \mathrm{p}=0.009)$. Gynecological history including age at menarche and menopause, and frequency of irregular periods did not differ between the groups. SLE patients reported a shorter duration of oral contraceptive (OCP) use, and no difference in postmenopausal hormone replacement therapy use as compared to controls.

When adjusted for age, data were not different from those presented in Table 1, except age at menopause $(\mathrm{p}=$ $0.02)$. Also, SLE women were less likely to use any contraception $(11 \%$ vs $4 \%, \mathrm{p}=0.03)$ and used OCP in similar numbers but for a shorter duration (56 vs 72 months, $\mathrm{p}=$ 0.0001). When adjusting for smoking on preterm birth, the relationships reported did not substantially change.

Our SLE cohort was primarily Caucasian, English speaking and fairly healthy. Ninety-five percent of our population was women, the mean age was $49.1 \pm$ SEM 1.3 years and the mean disease duration was $11.4 \pm$ SEM 1.3 years. The mean \pm SEM SLAM [5], SLICC [6] and SLEDAI [7] scores were, respectively, $8.5 \pm 0.3,1.3 \pm 0.4$ and $6.7 \pm 0.4$.

We assessed laboratory data from 36 patients in our SLE population: $92 \%$ had positive ANA, 56\% were positive for anti-double-stranded DNA (anti-dsDNA) and 21\% had antiphospholipid antibodies.

\section{REVIEW OF THE LITERATURE}

In total, 54 articles on lupus pregnancy published from 1963 to 2006 were reviewed [8-61]. Table 2 presents the results from the previously published studies compared to our present case-control study findings. Most of the results were similar between groups; however, we found that SLE flares (by self report) during pregnancy were less frequent in our population compared to the literature. Also, fewer patients from our study had prematurity or elective termination. Figs. $(\mathbf{1}, \mathbf{2})$ show results in median $(\%)$ for pregnancy outcome and SLE peripartum flares subdivided into 3 periods of publication date. Each time frame contains data from 18 publications. We noticed that over time, the rate of SLE peripartum flares has improved ( $\mathrm{p}=0.002)$, elective abortions (including termination for medical or personal reasons) have decreased, and the proportion of pregnancies resulting in live birth has increased $(\mathrm{p}=0.024)$. The frequency of fetal death (the sum of spontaneous abortions or miscarriage and stillbirths) has not significantly changed. Results in mean (\%) and median (\%) were similar (Table $\mathbf{3}$ ). 
Table 1. Subjects`Characteristics and Results of Our Case-Control Study

\begin{tabular}{|c|c|c|c|c|c|}
\hline & SLE N (\%) & Controls N (\%) & p-Value & OR & CI 95\% \\
\hline $\mathrm{N}$ & 108 & 134 & & & \\
\hline Age (years) & $42 \pm 1$ & $38 \pm 1$ & 0.37 & & \\
\hline Disease Duration (years) & $15 \pm 1$ & & & & \\
\hline $\begin{array}{l}\text { Educational level } \\
\text { High school } \\
\text { Above high school }\end{array}$ & $\begin{array}{l}52(48) \\
56(52) \\
\end{array}$ & $\begin{array}{c}26(19) \\
108(81)\end{array}$ & 0.0001 & 0.26 & $2.18-6.83$ \\
\hline $\begin{array}{l}\text { Marital Status } \\
\text { Never married } \\
\text { Married, Living Common-law, Widowed } \\
\text { Separated, Divorced, Remarried }\end{array}$ & $\begin{array}{l}15(14) \\
77(71) \\
16(15)\end{array}$ & $\begin{array}{l}25(19) \\
84(62) \\
25(19)\end{array}$ & 0.36 & & \\
\hline $\begin{array}{l}\text { Work experience } \\
\text { Homemaker } \\
\text { Working/Student }\end{array}$ & $\begin{array}{l}21(21) \\
81(79)\end{array}$ & $\begin{array}{c}11(9) \\
115(91)\end{array}$ & 0.01 & 2.7 & $1.24-5.93$ \\
\hline Ever pregnant & $83(77)$ & $93(69)$ & 0.15 & 1.5 & $0.85-2.73$ \\
\hline $\begin{array}{l}\text { Symptoms before last pregnancy } \\
\text { Yes } \\
\text { No } \\
\text { Unknown }\end{array}$ & $\begin{array}{c}25(30) \\
55(66) \\
3(4)\end{array}$ & & & & \\
\hline DM & $4(4)$ & $2(1.5)$ & 0.28 & & \\
\hline Hypertension & $23(22)$ & $18(13)$ & 0.10 & 1.76 & $0.90-3.48$ \\
\hline Thyroid Problems & $23(21)$ & $14(10)$ & 0.02 & 2.32 & $1.13-4.77$ \\
\hline Other Medical Problems & $57(54)$ & $57(43)$ & 0.09 & 1.55 & $0.93-2.59$ \\
\hline Onset of menarche (years) & $12.6 \pm 0.1$ & $12.2 \pm 0.2$ & 0.07 & & \\
\hline Menopausal & $40(38)$ & $32(24)$ & 0.02 & 1.93 & $1.11-3.38$ \\
\hline Age at menopause * & $42 \pm 1$ & $43 \pm 2$ & 0.37 & & \\
\hline Hysterectomy causing menopause in above group (\%) & $21(47)$ & $12(39)$ & 0.29 & 1.39 & $0.55-3.51$ \\
\hline $\begin{array}{l}\text { Hormone replacement therapy (ever used during meno- } \\
\text { pause) }\end{array}$ & $29(66)$ & $14(47)$ & 0.10 & 2.21 & $0.85-5.71$ \\
\hline Irregular periods in non-menopausal & 10 of $44(22)$ & 5 of $29(17)$ & 0.57 & 1.4 & $0.43-4.7$ \\
\hline Mean age at 1 st pregnancy (years) & $23 \pm 1$ & $24 \pm 1$ & 0.06 & & \\
\hline Number of pregnancies per woman & $2.3 \pm 0.2$ & $1.8 \pm 0.1$ & 0.17 & & \\
\hline Number of children & $2.33 \pm 0.1$ & $2.05 \pm 0.1$ & 0.72 & & \\
\hline Had child (ren) (\% out of those pregnant) & $78(93)$ & $89(95)$ & 0.60 & & \\
\hline No children & $5(5)$ & $4(5)$ & 0.74 & & \\
\hline Miscarriage (at least one) & $26(31)$ & $28(30)$ & 0.86 & 0.94 & $0.50-1.79$ \\
\hline Therapeutic abortion & $7(8)$ & $8(8)$ & 0.53 & 1.03 & $0.36-2.99$ \\
\hline Ever had a stillborn child & $1(1)$ & $0(0)$ & 0.22 & & \\
\hline Neonatal death ( $<3$ months $)$ & $4(5)$ & $1(1)$ & 0.13 & & \\
\hline At least one preterm birth & $20(24)$ & $5(5)$ & 0.0008 & 8.32 & $3.06-22.66$ \\
\hline Gestational Diabetes & $7(9)$ & $5(5)$ & 0.42 & 1.62 & $0.49-5.33$ \\
\hline High blood pressure / Toxemia during pregnancy & $23(28)$ & $20(22)$ & 0.36 & 1.38 & $0.69-2.75$ \\
\hline Smoked during pregnancy & $35(42)$ & $22(24)$ & 0.009 & 2.35 & $1.23-4.49$ \\
\hline Alcohol during pregnancy & $5(6)$ & $10(11)$ & 0.26 & 0.53 & $0.17-1.62$ \\
\hline Other health problems during pregnancy & $30(37)$ & $24(26)$ & 0.11 & 1.69 & $0.89-3.23$ \\
\hline
\end{tabular}


(Table 1) contd.....

\begin{tabular}{|c|c|c|c|c|c|}
\hline & SLE N (\%) & Controls N (\%) & p-Value & OR & CI $95 \%$ \\
\hline SLE flare during pregnancy & $10(18)$ & \multirow{2}{*}{\multicolumn{4}{|c|}{ As defined by patients }} \\
\hline SLE improved during pregnancy & $10(18)$ & & & & \\
\hline Contraception use (ever, any, including OCP) & $96(89)$ & $128(96)$ & 0.03 & 0.31 & $0.11-0.92$ \\
\hline OCP use & $66(49)$ & $47(44)$ & 0.38 & 0.8 & $0.48-1.32$ \\
\hline Duration of OCP use (mean \pm SEM in months) & $56 \pm 5.7$ & $72 \pm 5.5$ & 0.0001 & & $0.58-0.65$ \\
\hline Tubal Ligation & $33(32)$ & $30(23)$ & 0.11 & 1.60 & $0.89-2.85$ \\
\hline At least 6 months of infertility & $32(33)$ & $41(32)$ & 0.88 & 1.04 & $0.59-1.83$ \\
\hline Unable to have children because of infertility & $18(19)$ & $30(24)$ & 0.38 & 0.75 & $0.39-1.44$ \\
\hline Ever taken fertility medications & $5(5)$ & $5(4)$ & 0.73 & 1.25 & $0.35-4.44$ \\
\hline $\begin{array}{l}\text { Infertility problems - partner } \\
\text { Yes } \\
\text { No } \\
\text { Not known }\end{array}$ & $\begin{array}{c}5(5) \\
63(64) \\
31(31)\end{array}$ & $\begin{array}{c}6(5) \\
74(59) \\
45(36)\end{array}$ & 0.76 & 0.98 & $0.29-3.36$ \\
\hline
\end{tabular}

Results are given in \% or mean \pm SEM, unless indicated otherwise.

$\mathrm{OR}=$ odds ratios: SLE $v s$ controls

$\mathrm{OCP}=$ oral contraceptive pills

*Most were not menopausal, so age should increase over time

Table 2. Summary of Pregnancy Outcomes, Fertility Rate and Flares Presented in Mean $(\%) \pm$ SEM from Published Studies Compared to Our Present CaseControl Study Findings

\begin{tabular}{|c|c|c|c|c|}
\hline & $\mathbf{N}$ & $\begin{array}{l}\text { Literature } \\
\text { Review }\end{array}$ & $\begin{array}{c}\text { Present } \\
\text { Study-SLE } \\
\text { Cases }\end{array}$ & $\begin{array}{c}\text { Present } \\
\text { Study-Controls }\end{array}$ \\
\hline $\begin{array}{l}\text { Elective termination } \\
(\%)\end{array}$ & 44 & $10.5 \pm 1.5$ & 2.9 & 4.0 \\
\hline Fetal wastage (\%) & 45 & $19.5 \pm 1.6$ & 18.3 & 16.6 \\
\hline Neonatal death $(\%)$ & 39 & $2.2 \pm 0.4$ & 1.7 & 0.4 \\
\hline Preterm birth (\%) & 43 & $25.5 \pm 2.2$ & 9.5 & 4.9 \\
\hline Full term birth (\%) & 44 & $49.0 \pm 2.5$ & 69.3 & 74.5 \\
\hline Live birth (\%) & 50 & $72.3 \pm 1.9$ & 78.8 & 79.4 \\
\hline $\begin{array}{l}\text { Pregnancy rate } \\
\text { (mean) }\end{array}$ & 7 & $2.3 \pm 0.08$ & $2.3 \pm 0.2$ & $1.8 \pm 0.1$ \\
\hline $\begin{array}{l}\text { Flares during } \\
\text { pregnancy }(\%)\end{array}$ & 38 & $28.6 \pm 2.6$ & 18 & \\
\hline $\begin{array}{l}\text { Flare-up postpartum } \\
(\%)\end{array}$ & 24 & $11.9 \pm 2.0$ & & \\
\hline Total flares (\%) & 39 & $36.5 \pm 3.3$ & & \\
\hline IUGR (\%) & 20 & $14.8 \pm 0.8$ & & \\
\hline $\begin{array}{l}\text { Preg-induced HTN } \\
(\%)\end{array}$ & 17 & $15.9 \pm 2.7$ & $19.3 *$ & $17.2 *$ \\
\hline $\begin{array}{l}\text { Gestational DM } \\
(\%)\end{array}$ & 8 & $6.7 \pm 1.6$ & 7.2 & 5.4 \\
\hline APL ab $(\%)$ & 13 & $36.8 \pm 6.1$ & & \\
\hline Neonatal lupus (\%) & 25 & $2.4 \pm 0.6$ & & \\
\hline
\end{tabular}

Elective termination= termination for personal or medical reasons

Fetal wastage $=$ sum of miscarriages or spontaneous abortions and stillborn

IUGR= Intrauterine growth restriction

Pregnancy rate $=$ number of pregnancies per woman

Preg-induced HTN = pregnancy-induced hypertension

Gestational DM= gestational diabetes

APL $a b=$ antiphospholipid antibodies

* Sum of pregnancy-induced hypertension and toxemia

$\mathrm{N}=$ number of publications.

\section{FERTILITY RATE}

Fertility is defined as the ability to become pregnant. Seven publications $[12,33,35,37-38,45,59]$ demonstrated that the fertility rate in SLE is usually unaffected and comparable to the general population. Pregnancy rate (number of pregnancies per patient) varied from 2.0 to 2.6 (mean $2.3 \pm$ SEM 0.08) (Table 2). However, certain factors predispose some SLE women to lower fertility. Severe renal failure and use of high doses of steroids might lead to menstrual irregularities or even amenorrhea [62]. In addition, previous treatment with alkylating agents can lead to ovarian failure [63]. Cyclophosphamide-induced premature ovarian failure is well documented. In fact, the incidence of ovarian failure is related to the age when starting cyclophosphamide, the duration of use and the cumulative dose [64-69]. In a retrospective series of 39 SLE patients who had received intermittent pulses of cyclophosphamide therapy, Boumpas et al. reported that sustained amenorrhea occurred in $12 \%$ of patients $<25$ year of age, in $27 \%$ of patients between 26 to 30 years old and in $62 \%$ of patients older than 31years [64]. In a study of 67 SLE premenopausal women who were treated with monthly intravenous cyclophosphamide, $31 \%$ developed sustained amenorrhea of at least 12 months. In this same study, the cumulative dose of cyclophosphamide resulting in sustained amenorrhea in 50\% and 90\% of the women (D50 and D90) was $8 \mathrm{~g} / \mathrm{m}^{2}$ and $12 \mathrm{~g} / \mathrm{m}^{2}$, respectively [68].

In order to preserve fertility and to minimize cyclophosphamide gonadotoxicity, an adjuvant treatment with gonadotropin-releasing hormone agonistic analogue ( $\mathrm{GhRH}-\mathrm{a})$ may be an option [70-71], although this is not widely adopted. Some clinics use oral contraceptive pills to prevent ovulation as theoretically having less risk to an anovulatory ovary. There are trials of exogenous estrogen and lupus flare, and both contraceptive hormones and post menopausal hormones in RCTs seem to be relatively safe. There are some contraindications for hormone use in young women with lupus such as known hypercoaguable state, and some relative contraindications such as migraines, hypertension and smoking $[72,73]$. 


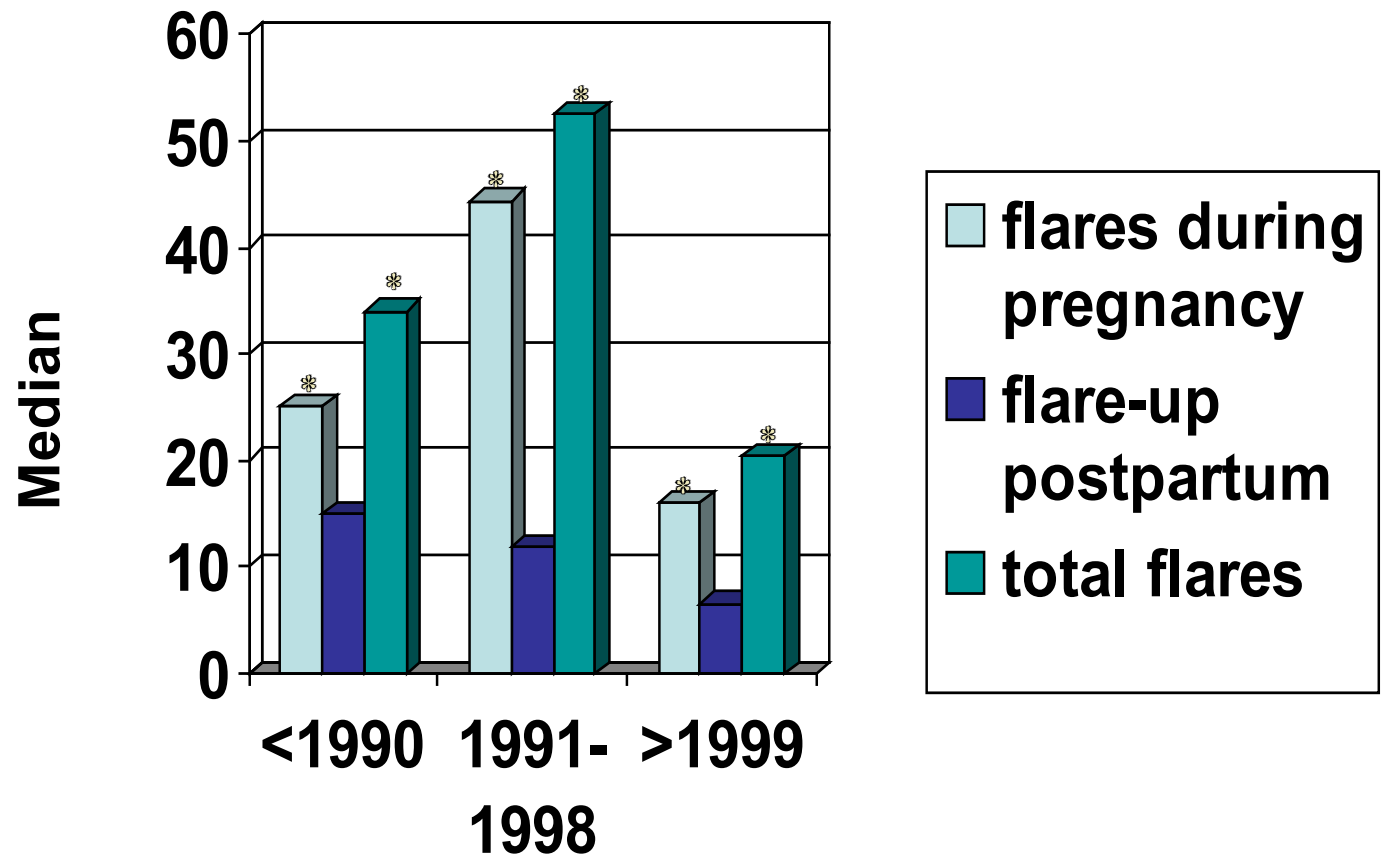

\section{Publication date}

"p-value between groups $=0.002$

Fig. (1). The frequency of SLE peripartum flares in the literature prior to $1990 \mathrm{vs}$ most recent data.

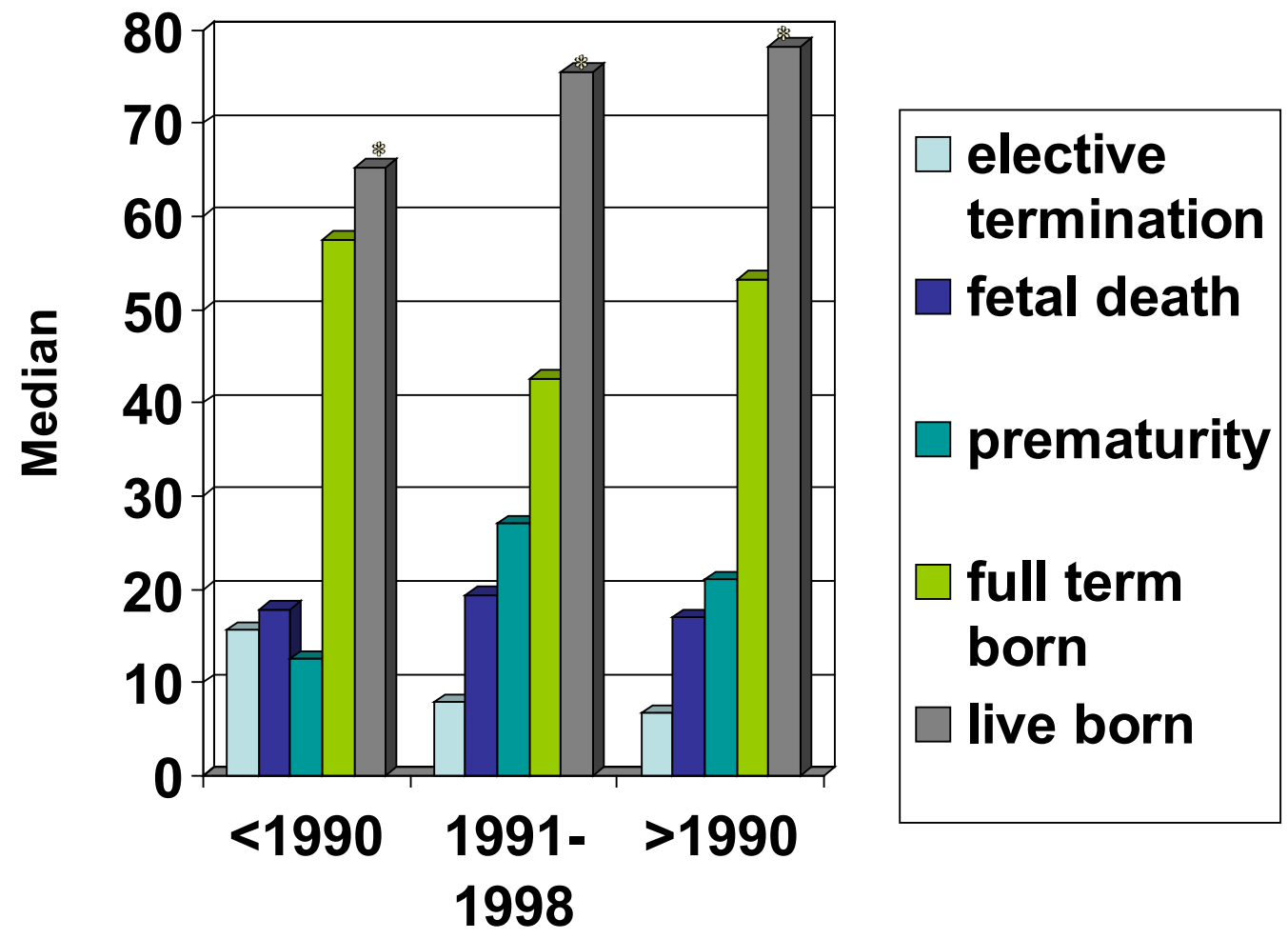

Publication date

p-value between groups $=0.024$

Fig. (2). The frequency of SLE pregnancy outcomes in the literature prior to $1990 \mathrm{vs}$ most recent data. 
Table 3. Literature Summary: SLE Peripartum Flares and Pregnancy Outcomes Presented in Mean \% \pm SEM and Median \% with Interquartile Range (IQR) for Each Time Period

\begin{tabular}{|c|c|c|c|c|c|}
\hline & & $\mathbf{N}$ & Mean \pm SEM \% & Median \pm IQR \% & p-Value Between Groups \\
\hline \multirow{2}{*}{ Flares during pregnancy } & $<1990$ & 13 & $25.9 \pm 2.9$ & $25.0 \pm 10.4$ & \multirow{2}{*}{0.002} \\
\hline & $>1999$ & 14 & $20.7 \pm 4.0$ & $16.0 \pm 9.1$ & \\
\hline \multirow{2}{*}{ Flare-up postpartum } & $<1990$ & 8 & $16.3 \pm 4.0$ & $15.0 \pm 22.3$ & \multirow{2}{*}{ NS } \\
\hline & $>1999$ & 8 & $6.3 \pm 2.2$ & $6.6 \pm 10.1$ & \\
\hline \multirow{3}{*}{ Total flares } & $<1990$ & 13 & $35.9 \pm 5.0$ & $34.0 \pm 27.2$ & \multirow{3}{*}{0.002} \\
\hline & $1991-1998$ & 12 & $51.4 \pm 6.0$ & $52.5 \pm 31.1$ & \\
\hline & $>1999$ & 14 & $24.3 \pm 4.1$ & $20.5 \pm 20.0$ & \\
\hline \multirow{3}{*}{ Fetal wastage } & $<1990$ & 15 & $23.0 \pm 3.5$ & $17.9 \pm 30.0$ & \multirow{3}{*}{ NS } \\
\hline & 1991-1998 & 13 & $18.9 \pm 2.5$ & $19.4 \pm 15.5$ & \\
\hline & $>1999$ & 17 & $16.8 \pm 2.1$ & $17.0 \pm 15.1$ & \\
\hline \multirow{3}{*}{ Prematurity } & $<1990$ & 11 & $19.1 \pm 4.4$ & $12.5 \pm 25.3$ & \multirow{3}{*}{ NS } \\
\hline & 1991-1998 & 15 & $31.4 \pm 3.5$ & $27.0 \pm 25.7$ & \\
\hline & $>1999$ & 17 & $24.5 \pm 3.2$ & $21.0 \pm 17.7$ & \\
\hline \multirow[b]{2}{*}{ Full term birth } & $<1990$ & 12 & $50.4 \pm 5.7$ & $57.5 \pm 35.6$ & \multirow[b]{2}{*}{ NS } \\
\hline & 1991-1998 & 15 & $43.3 \pm 3.2$ & $42.6 \pm 25.6$ & \\
\hline
\end{tabular}

$\mathrm{N}=$ number of publications, $\mathrm{NS}=$ non-significant.

\section{PREGNANCY OUTCOME}

Various publications have reported an increased incidence of prematurity, fetal death (the sum of spontaneous abortions or miscarriage and stillbirths) and intrauterine grown retardation (IUGR) in SLE. Dhar et al. reviewed 16 studies on pregnancy outcomes before and after the diagnosis of SLE [74] and found that, in spite of some limitations in study design and statistical analysis and variations in terminology used, most studies concluded that pregnancy loss $[8$, $21,31,34,35,37,38,48,50,56,51,70,71,74]$, preterm births $[8,21,31,34,38,48,49,51,74$, $]$ and IUGR $[8,31$, $33,34]$ were more common after than before the diagnosis of SLE and compared to a control population.

From our review of 45 studies [9-15, 17-30, 32-34, 36, $39,40,42,45-61]$, the frequency of fetal death varied from $4 \%$ to $43 \%$ (mean $19.5 \% \pm$ SEM $1.6 \%$ ) (Table 2 ), which is higher than in the general population [21, 31, 32, 35, 37]. In another study, the authors reported a 4-fold increase in the risk of stillbirth in lupus patients. They also found that the risk was halved if they excluded patients with central nervous system (CNS) disease [74]. Further investigation is needed to confirm this correlation in lupus pregnancy. Several factors may predict fetal death such as lupus disease activity, active lupus nephritis [22], and the presence of antiphospholipid antibodies.

Fetal prognosis depends mostly on disease activity, with fetal loss ranging from $25-52 \%$ in patients with active SLE compared to $8-12 \%$ in patients with inactive SLE at the onset of pregnancy. The latter rate is comparable to observations in healthy women [17-21].

Active renal disease has been associated with $8-24 \%$ of fetal loss from miscarriages [23] and 4-24\% of stillbirths and neonatal deaths [17, 19, 22-25]. Thus, active lupus nephritis patients are often advised to avoid pregnancy. However, during inactive SLE, the pregnancy outcome is usually favorable $[17,19]$. Rahman et al. reported on a series of 141 SLE pregnancies where maternal active renal disease was present in 33\% of pregnancies resulting in fetal loss vs $13 \%$ of pregnancies with live births $(p<0.012)$ [22]. In SLE patients a history of nephritis, maternal hypertension (OR 6.4), proteinuria $>0.5 \mathrm{~g} /$ day $(\mathrm{OR} 13.3)$ and the presence of antiphospholipid antibodies (OR 17.8) have been shown to be predic- 
tive of adverse fetal outcome [20]. Another report from Hong Kong analyzed a subgroup of 27 patients with a past history of lupus nephritis; they found that significant proteinuria $(p=0.01)$ and active disease $(p=0.03)$ at conception and during the gestation were predictive of poor fetal outcome [75].

Antiphospholipid antibodies are present in $36.8 \% \pm$ SEM $6.1 \%$ of SLE patients in 13 publications [15, 16, 19-21, 2628, 47, 49, 52, 60, 61] (Table 2). The association between these antibodies and fetal loss has been well demonstrated $[10,23]$. Mok et al. studied 91 pregnancies, reporting that antiphospholipid antibodies were more prevalent in patients with recurrent miscarriages $(\mathrm{p}=0.008, \mathrm{OR}=14.3)$ and the strongest predictive factor was the presence of lupus anticoagulant ( $\mathrm{p}=0.002$, OR 23.3) [75]. Mechanisms could include lack of implantation, placental vasoconstriction and thrombosis leading to either fetal growth restriction or death $[23,76]$. The literature indicates that the presence of these antibodies is associated with an approximately 2 -fold increase in fetal loss (as high as $30-83 \%$ of pregnancies compared to a $4-43 \%$ fetal loss rate in antiphospholipid antibody negative SLE patients) $[20,23,51,77-78]$. Fetal outcome is significantly improved with the use of heparin and low dose aspirin in these cases [79-80]. A recent review by Erkan et al. summarized the current evidence on the management of antiphospholipid syndrome in pregnancy [81].

Lupus is associated with an increased rate of prematurity. Preterm delivery frequency in the general population varies between $4 \%$ and $9 \%[9,23,30,35,42]$. Our analysis of 43 studies found a mean of $25.5 \% \pm$ SEM $2.2 \%$, with a range of $4 \%$ to $62 \%$ [8-16, 17-25, 27-29, 30-34, 38-40, 42-43, 46-49, 51-60] (Table 2). The discrepancies in the literature in terms of frequency of prematurity in SLE might be due to differences in definitions of prematurity, the rate of therapeutic or spontaneous abortions and the fact that preterm birth in SLE has multiple causes. Reasons for prematurity seem to be SLE activity [9-10, 15, 32, 47, 52, 55, 75], maternal hypertension $[15,21,22,32,82]$, history of fetal loss [15], pre-eclampsia [19], antiphospholipid antibodies [9-10, 30], placental insufficiency and an increased prevalence of premature rupture of the membranes [28, 83].

Several studies mentioned that corticosteroid use during pregnancy increased the risk of preterm birth $[9,10,15,47$, $50,55]$. Indeed, a retrospective study demonstrated a correlation between the use of $>10 \mathrm{mg} /$ day of prednisone in SLE pregnant women and an increased rate of preterm births [9]. However, this could be confounded by SLE disease activity. A study from Japan showed the frequency of preterm delivery in patients receiving $>15 \mathrm{mg} /$ day of prednisone was $60 \%$ vs $13 \%$ in patients who received $0-15 \mathrm{mg} /$ day $(\mathrm{p}<0.05)$ [55]. However, a higher dosage of corticosteroid is often necessary to control disease activity, which may also contribute to premature delivery. In addition, corticosteroids may impair the placental function and induce premature rupture of membranes.

Three randomized trials have evaluated the usefulness of corticosteroids in pregnant women with unexplained or antiphospholipid antibody-associated fetal loss. All concluded that corticosteroids did not improve fetal outcome. On the contrary, the treatment group had a significantly increased rate of preterm births and maternal morbidities or obstetrical complications such as hypertension, diabetes mellitus, preeclampsia and premature rupture of the membranes $[44,84-$ 86].

Intrauterine growth restriction (IUGR) occurs in $14.8 \% \pm$ $2.0 \%$ of SLE pregnancies in 20 studies $[8,10,11,15,19,22$, $26,27,30-32,39,42,47,53,57-61]$. The main factors contributing to the increased rate of growth restriction are hypertension [15, 22], corticosteroids, antiphospholipid antibodies $[10,76]$ and pre-eclampsia $[19,22,36,83,87]$. Low complement levels also seem to correlate with IUGR $[15,55]$.

\section{LUPUS FLARES}

Diagnosis of a lupus flare in pregnancy may be difficult; normal physiological changes or pregnancy related complications such as pre-eclampsia can mimic a lupus flare. The effect of pregnancy on SLE activity has received much attention; however, the exact consequence of pregnancy on the course of SLE is not conclusively determined. Some authors have reported an increased frequency of flares [42-44], but others have found a rate similar to a non-pregnant SLE population [40-41]. Differences in the definitions of lupus flare, as well as patient or control group characteristics might contribute to these contradictory results. Overall, we found that lupus flares are common in pregnancy: our analysis of 39 publications showed a mean rate of lupus reactivation of $36.5 \% \pm 3.3 \%$ (Table 2) $[10,11,13,15,17,18,20,22,25$, $28,32-35,30,42-44,49,53-56,59-61]$.

Some factors might increase the risk of flares. Most studies agreed that flares occurred more often in SLE patients with active disease at conception $[17,18,54-56,59]$. A publication from Japan noted the frequency of SLE flares was $13 \%$ in inactive patients at conception vs $75 \%$ in patients with active disease [55]. Moroni et al. reported fetal and maternal outcomes of 51 pregnancies in women with a history of lupus nephritis. They demonstrated that the only predictor of renal flare was the presence of any sign of renal disease activity at the onset of pregnancy. Indeed, renal flares occurred in $5 \%$ of patients with quiescent renal disease compared to $39 \%$ in patients with active renal disease $(\mathrm{p}=0.01)$ [20]. In addition, the literature has shown that flares might occur in any trimester or during the post-partum period [32, 42-44]. Usually, the severity of the flare is mild with arthritis, constitutional and cutaneous manifestations being common [5, 43]. However, more serious problems affecting the kidneys and central nervous system have been reported in $46 \%$ and $14 \%$ of patients, respectively [32, 42-43]. Therefore, close monitoring and multidisciplinary care are essential during the pregnancy and post-partum period.

Serum prolactin normally rises early in pregnancy and persists at a high level through the breast-feeding period. Several publications have attempted to establish a relationship between hyperprolactinemia and lupus disease activity, but results have been contradictory [88-95]. To our knowledge, only one case report has been published on breastfeeding and lupus reactivation postpartum [96]. Actually, there is no evidence of postpartum SLE exacerbation by breast-feeding.

\section{DISCUSSION}

The findings from our case-control study were compared to those from the literature. We found no statistical differ- 
ence between the SLE vs control group for fertility rate, gynecological history and pregnancy outcome except for prematurity (Table 1). More SLE women had preterm delivery compared to the control population. When we adjusted for possible confounding variables for each pregnancy outcome, we obtained a lower frequency of preterm birth and elective termination (Table 2). Also, lupus flares in our cohort during the course of pregnancy were lower than reported from the literature. Differences might be related to the characteristics of our study population, as age, ethnicity, disease status, treatment and personal information (such as occupation, education and living conditions) can influence clinic outcomes significantly.

The diagnosis of SLE was confirmed for cases in our study but obstetrical chart review was not done. However, we presume the data are reliable as most women recall their reproductive history accurately and it is unlikely that recall bias will have a significant influence on the accuracy of results. Also, our results were generally consistent with the current literature.

We found that SLE subjects were more likely than controls to have thyroid problems (Table 1), and thyroid disease is known to be more common in SLE [97-99]. We did not assess the temporal relationship between thyroid disease and SLE pregnancy, as the timing of thyroid disease onset and pregnancies was not determined. A limitation could be that many of our patients had their pregnancies prior to being diagnosed with SLE.

Other co-morbidities were similar with the exception of smoking during pregnancy, which was higher in SLE women. Education (such as counseling about conception to be planned while the lupus is inactive for a better outcome for mother and baby) and close monitoring of pregnant patients may positively impact on the outcome. Although we did not find smoking as a risk in our population for adverse pregnancy outcome, it is obvious that smoking cessation should be encouraged in those contemplating pregnancy and during pregnancy. This study was likely underpowered to demonstrate ill effects of smoking in lupus such as small-fordates babies.

From the 54 published papers we reviewed altogether, in spite of some differences in the study populations, design, and definitions used for pregnancy outcomes or lupus reactivation, we assessed in total 3740 SLE pregnancies. The literature showed an improvement in fetal and maternal outcome since the last decade (Figs. 1, 2 and Table 3). Moroni et al. retrospectively analyzed fetal and maternal outcomes in SLE patients with lupus nephritis, noting that fetal loss has decreased from $46 \%$ to $30 \%$ since the 1970 s [20]. Furthermore, treatment with heparin of patients who have antiphospholipid antibodies began in 1989. A higher rate of live birth $(71 \%$ vs 30\%) $(\mathrm{p}=0.0013)$ was observed by CortésHernández et al. since the induction of this new therapy in these patients [10]. Obviously, important progress made in maternal disease control and improvements in obstetrical care have contributed to better fetal outcomes.

The are several other possible reasons that pregnancy outcomes may be improving over time including: less severe SLE over time; more mild patients being diagnosed; conception counseling about timing of pregnancy when SLE is in- active; better multidisciplinary care; increased contraception use in ill patients; and a trend for better pregnancy outcome for all women in the general population.

\section{CONCLUSIONS}

This article summarizes much of the information available on pregnancy outcomes in SLE and adds data from our cohort of women with SLE. Fertility is not affected in SLE patients; however, despite recent progress in obstetrical care, maternal and fetal complications still exist. Pregnancy in SLE patients should be considered as a high-risk pregnancy and conception should be planned, if possible, during a quiescent period. Close monitoring for optimal disease control and multidisciplinary obstetrical care are necessary throughout the gestation period to increase the chances of a successful pregnancy.

\section{REFERENCES}

[1] Donaldson LB, De Alvarez RR. Further observations on lupus erythematosus associated with pregnancy. Am J Obstet Gynecol 1962; 83: 1461-73.

[2] Ellis FA, Bereston ES. Lupus erythematosus associated with pregnancy and menopause. AMA Arch Derm Syphilol 1952; 65: 170-6.

[3] Cervera R, Font J, Carmona F, Balasch J. Pregnancy outcome in systemic lupus erythematosus: good news for the new millennium. Autoimmun Rev 2002; 1: 354-9.

[4] Tan EM, Cohen AS, Fries JF, et al. The 1982 revised criteria for the classification of systemic lupus erythematosus. Arthritis Rheum 1982; 25: 1271-7.

[5] Bae SC, Koh HK, Chang DK, Kim MH, Park JK, Kim SY. Reliability and validity of systemic lupus activity measure-revised (SLAM-R) for measuring clinical disease activity in systemic lupus erythematosus. Lupus 2001; 10: 405-9.

[6] Urowitz MB, Gladman DD. Measures of disease activity and damage in SLE. Baillieres Clin Rheumatol 1998; 12: 405-13.

[7] Guzman J, Cardiel MH, Arce-Salinas A, Sanchez-Guerrero J, Alarcon-Segovia D. Measurement of disease activity in systemic lupus erythematosus. Prospective validation of 3 clinical indices. J Rheumatol 1992; 19: 1551-8.

[8] Yasmeen S, Wilkins EE, Field NT, Sheikh RA, Gilbert WM. Pregnancy outcomes in women with systemic lupus erythematosus. J Matern Fetal Med 2001; 10: 91-6.

[9] Clark CA, Spitzer KA, Nadler JN, Laskin CA. Preterm deliveries in women with systemic lupus erythematosus. J Rheumatol 2003; 30: 2127-32.

[10] Cortes-Hernandez J, Ordi-Ros J, Paredes F, Casellas M, Castillo F, Vilardell-Tarres M. Clinical predictors of fetal and maternal outcome in systemic lupus erythematosus: a prospective study of 103 pregnancies. Rheumatology (Oxford) 2002; 41: 643-50.

[11] Kari JA. Pregnancy outcome in connective tissue diseases. Saudi Med J 2001; 22: 590-4.

[12] Hardy CJ, Palmer BP, Morton SJ, Muir KR, Powell RJ. Pregnancy outcome and family size in systemic lupus erythematosus: a casecontrol study. Rheumatology (Oxford) 1999; 38: 559-63.

[13] Sittiwangkul S, Louthrenoo W, Vithayasai P, Sukitawut W. Pregnancy outcome in Thai patients with systemic lupus erythematosus. Asian Pac J Allergy Immunol 1999; 17: 77-83.

[14] Kleinman D, Katz VL, Kuller JA. Perinatal outcomes in women with systemic lupus erythematosus. J Perinatol 1998; 18: 178-82.

[15] Le Thi Huong D, Wechsler B, Piette JC, Bletry O, Godeau P. Pregnancy and its outcome in systemic lupus erythematosus. QJM 1994, 87: 721-9.

[16] Tincani A, Faden D, Tarantini M, et al. Systemic lupus erythematosus and pregnancy: a prospective study. Clin Exp Rheumatol 1992; 10: 439-46.

[17] Jungers P, Dougados M, Pelissier C, et al. Lupus nephropathy and pregnancy. Report of 104 cases in 36 patients. Arch Intern Med 1982; 142: 771-6.

[18] Hayslett JP, Lynn RI. Effect of pregnancy in patients with lupus nephropathy. Kidney Int 1980; 18: 207-20. 
[19] Julkunen H, Kaaja R, Palosuo T, Gronhagen-Riska C, Teramo K. Pregnancy in lupus nephropathy. Acta Obstet Gynecol Scand 1993; 72: 258-63.

[20] Moroni G, Quaglini S, Banfi G, et al. Pregnancy in lupus nephritis. Am J Kidney Dis 2002; 40: 713-20.

[21] Petri M, Allbritton J. Fetal outcome of lupus pregnancy: a retrospective case-control study of the Hopkins Lupus Cohort. J Rheumatol 1993; 20 (4): 650-6.

[22] Rahman P, Gladman DD, Urowitz MB. Clinical predictors of fetal outcome in systemic lupus erythematosus. J Rheumatol 1998; 25 (8): 1526-30.

[23] Packham DK, Lam SS, Nicholls K, Fairley KF, Kincaid-Smith PS. Lupus nephritis and pregnancy. Q J Med 1992; 83: 315-24.

[24] Oviasu E, Hicks J, Cameron JS. The outcome of pregnancy in women with lupus nephritis. Lupus 1991; 1 (1): 19-25.

[25] Imbasciati E, Surian M, Bottino S, et al. Lupus nephropathy and pregnancy. A study of 26 pregnancies in patients with systemic lupus erythematosus and nephritis. Nephron 1984; 36: 46-51.

[26] Englert HJ, Derue GM, Loizou S, et al. Pregnancy and lupus: prognostic indicators and response to treatment. Q J Med 1988; 66: 125-36.

[27] Molad Y, Borkowski T, Monselise A, et al. Maternal and fetal outcome of lupus pregnancy: a prospective study of 29 pregnancies. Lupus 2005; 14: 145-51.

[28] Aggarwal N, Sawhney H, Vasishta K, Chopra S, Bambery P. Pregnancy in patients with systemic lupus erythematosus. Aust N Z J Obstet Gynaecol 1999; 39: 28-30.

[29] Johns KR, Morand EF, Littlejohn GO. Pregnancy outcome in systemic lupus erythematosus (SLE): a review of 54 cases. Aust N Z J Med 1998; 28: 18-22.

[30] Le Huong D, Wechsler B, Vauthier-Brouzes D, et al. Outcome of planned pregnancies in systemic lupus erythematosus: a prospective study on 62 pregnancies. Br J Rheumatol 1997; 36: 772-7.

[31] Julkunen H, Jouhikainen T, Kaaja R, et al. Fetal outcome in lupus pregnancy: a retrospective case-control study of 242 pregnancies in 112 patients. Lupus 1993; 2: 125-31.

[32] Mintz G, Niz J, Gutierrez G, Garcia-Alonso A, Karchmer S. Prospective study of pregnancy in systemic lupus erythematosus. Results of a multidisciplinary approach. J Rheumatol 1986; 13: 732-9.

[33] Nossent HC, Swaak TJ. Systemic lupus erythematosus. VI. Analysis of the interrelationship with pregnancy. J Rheumatol 1990; 17: 771-6.

[34] Gimovsky ML, Montoro M, Paul RH. Pregnancy outcome in women with systemic lupus erythematosus. Obstet Gynecol 1984; 63: 686-92.

[35] Fraga A, Mintz G, Orozco J, Orozco JH. Sterility and fertility rates, fetal wastage and maternal morbidity in systemic lupus erythematosus. J Rheumatol 1974; 1: 293-98.

[36] Fine L, Barnett EV, Danovitch GM, et al. Systemic lupus erythematosus in pregnancy. Ann Intern Med 1981, 94: 667-677.

[37] McHugh NJ, Reilly PA, McHugh LA. Pregnancy outcome and autoantibodies in connective tissue disease. J Rheumatol 1989; 16: 42-6.

[38] Siamopoulou-Mavridou A, Manoussakis MN, Mavridis AK, Moutsopoulos HM. Outcome of pregnancy in patients with autoimmune rheumatic disease before the disease onset. Ann Rheum Dis 1988; 47: 982-7.

[39] Huong DL, Wechsler B, Vauthier-Brouzes D, Beaufils H, Lefebvre G, Piette JC. Pregnancy in past or present lupus nephritis: a study of 32 pregnancies from a single centre. Ann Rheum Dis 2001; 60: 599-604.

[40] Lockshin MD, Reinitz E, Druzin ML, Murrman M, Estes D. Lupus pregnancy. Case-control prospective study demonstrating absence of lupus exacerbation during or after pregnancy. Am J Med 1984; 77: 893-8.

[41] Urowitz MB, Gladman DD, Farewell VT, Stewart J, McDonald J. Lupus and pregnancy studies. Arthritis Rheum 1993; 36: 1392-7.

[42] Wong KL, Chan FY, Lee CP. Outcome of pregnancy in patients with systemic lupus erythematosus. A prospective study. Arch Intern Med 1991; 151: 269-73.

[43] Petri M, Howard D, Repke J. Frequency of lupus flare in pregnancy. The Hopkins Lupus Pregnancy Center experience. Arthritis Rheum 1991; 34: 1538-45.

[44] Ruiz-Irastorza G, Lima F, Alves J, et al. Increased rate of lupus flare during pregnancy and the puerperium: a prospective study of 78 pregnancies. Br J Rheumatol 1996; 35: 133-8.
[45] Kaufman RL, Kitridou RC. Pregnancy in mixed connective tissue disease: comparison with systemic lupus erythematosus. J Rheumatol 1982; 9: 549-55.

[46] Tozman EC, Urowitz MB, Gladman DD. Systemic lupus erythematosus and pregnancy. J Rheumatol 1980; 7: 624-32.

[47] Chakravarty EF, Colon I, Langen ES, et al. Factors that predict prematurity and preeclampsia in pregnancies that are complicated by systemic lupus erythematosus. Am J Obstet Gynecol 2005; 192: 1897-904.

[48] Mund A, Simson J, Rothfield N. Effect of pregnancy on course of systemic lupus erythematosus. JAMA 1963; 183: 917-20.

[49] Rubbert A, Pirner K, Wildt L, Kalden JR, Manger B. Pregnancy course and complications in patients with systemic lupus erythematosus. Am J Reprod Immunol 1992; 28: 205-7.

[50] Grigor RR, Shervington PC, Hughes GR, Hawkins DF. Outcome of pregnancy in systemic lupus erythematosus. Proc R Soc Med 1977; 70: $99-100$.

[51] Kiss E, Bhattoa HP, Bettembuk P, Balogh A, Szegedi G. Pregnancy in women with systemic lupus erythematosus. Eur J Obstet Gynecol Reprod Biol 2002; 101 (2): 129-34.

[52] Georgiou PE, Politi EN, Katsimbri P, Sakka V, Drosos AA. Outcome of lupus pregnancy: a controlled study. Rheumatology (Oxford) $2000 ; 39:$ 1014-9.

[53] Lima F, Buchanan NM, Khamashta MA, Kerslake S, Hughes GR. Obstetric outcome in systemic lupus erythematosus. Semin Arthritis Rheum 1995; 25: 184-92.

[54] Jungers P, Dougados M, Pelissier C, et al. Problems posed by pregnancy in women with lupus nephropathy. Presse Med 1983; 12: 345-9.

[55] Kobayashi N, Yamada H, Kishida T, et al. Hypocomplementemia correlates with intrauterine growth retardation in systemic lupus erythematosus. Am J Reprod Immunol 1999; 42: 153-9.

[56] Bobrie G, Liote F, Houillier P, Grunfeld JP, Jungers P. Pregnancy in lupus nephritis and related disorders. Am J Kidney Dis 1987; 9: 339-43.

[57] Wong CH, Chen TL, Lee CS, Lin CJ, Chen CP. Outcome of pregnancy in patients with systemic lupus erythematosus. Taiwan J Obstet Gynecol 2006; 45: 120-3.

[58] Tan LK, Tan HK, Lee CT, Tan AS. Outcome of pregnancy in Asian women with systemic lupus erythematosus: experience of a single perinatal centre in Singapore. Ann Acad Med Singapore 2002; 31: 290-5.

[59] De Bandt M, Palazzo E, Belmatoug N, et al. Outcome of pregnancies in lupus: experience at one center. Ann Med Interne (Paris) 2000; 151: 87-92.

[60] Carmona F, Font J, Cervera R, Munoz F, Cararach V, Balasch J Obstetrical outcome of pregnancy in patients with systemic Lupus erythematosus. A study of 60 cases. Eur J Obstet Gynecol Reprod Biol 1999; 83: 137-42.

[61] Derksen RH, Bruinse HW, de Groot PG, Kater L. Pregnancy in systemic lupus erythematosus: a prospective study. Lupus 1994; 3 : 149-55.

[62] Buyon J, Wallace D. The endocrine system, use of exogenous estrogens, and the urogenital tract, in Dubois' lupus erythematosus. B. Hahn, Ed., Williams \& Wilkins: Baltimore, 1997, pp. 817-834.

[63] Langevitz P, Klein L, Pras M, Many A. The effect of cyclophosphamide pulses on fertility in patients with lupus nephritis. Am J Reprod Immunol 1992; 28: 157-8.

[64] Boumpas DT, Austin HA 3rd, Vaughan EM, Yarboro CH, Klippel $\mathrm{JH}$, Balow JE. Risk for sustained amenorrhea in patients with systemic lupus erythematosus receiving intermittent pulse cyclophosphamide therapy. Ann Intern Med 1993; 119: 366-9.

[65] McDermott EM, Powell RJ. Incidence of ovarian failure in systemic lupus erythematosus after treatment with pulse cyclophosphamide. Ann Rheum Dis 1996; 55: 224-9.

[66] Mok CC, Lau CS, Wong RW. Risk factors for ovarian failure in patients with systemic lupus erythematosus receiving cyclophosphamide therapy. Arthritis Rheum 1998; 41: 831-7.

[67] Huong DL, Amoura Z, Duhaut P, et al. Risk of ovarian failure and fertility after intravenous cyclophosphamide. A study in 84 patients. J Rheumatol 2002; 29: 2571-6.

[68] Ioannidis JP, Katsifis GE, Tzioufas AG, Moutsopoulos HM. Predictors of sustained amenorrhea from pulsed intravenous cyclophosphamide in premenopausal women with systemic lupus erythematosus. J Rheumatol 2002; 29: 2129-35. 
[69] Slater CA, Liang MH, McCune JW, Christman GM, Laufer MR. Preserving ovarian function in patients receiving cyclophosphamide. Lupus 1999; 8: 3-10.

[70] Blumenfeld Z. Preservation of fertility and ovarian function and minimalization of chemotherapy associated gonadotoxicity and premature ovarian failure: the role of inhibin-A and -B as markers. Mol Cell Endocrinol 2002; 187: 93-105.

[71] Blumenfeld Z, Shapiro D, Shteinberg M, Avivi I, Nahir M. Preservation of fertility and ovarian function and minimizing gonadotoxicity in young women with systemic lupus erythematosus treated by chemotherapy. Lupus 2000; 9: 401-5.

[72] Petri M, Kim MY, Kalunian KC, Grossman J, Hahn BH, Sammaritano LR. OC-SELENA Trial. Combined oral contraceptives in women with systemic lupus erythematosus. N Engl J Med 2005; 353 (24): 2550-8.

[73] Sánchez-Guerrero J, González-Pérez M, Durand-Carbajal M, et al. Menopause hormonal therapy in women with systemic lupus erythematosus. Arthritis Rheum 2007; 56 (9): 3070-9.

[74] Dhar JP, Essenmacher LM, Ager JW, Sokol RJ. Pregnancy outcomes before and after a diagnosis of systemic lupus erythematosus. Am J Obstet Gynecol 2005; 193: 1444-55.

[75] Mok MY, Leung PY, Lao TH, et al. Clinical predictors of fetal and maternal outcome in Chinese patients with systemic lupus erythematosus. Ann Rheum Dis 2004; 63: 1705-6.

[76] Pierangeli SS, Harris EN. A quarter of a century in anticardiolipin antibody testing and attempted standardization has led us to here, which is? Semin Thromb Hemost 2008; 34 (4): 313-28.

[77] Ramsey-Goldman R, Kutzer JE, Kuller LH, Guzick D, Carpenter AB, Medsger TA, Jr. Pregnancy outcome and anti-cardiolipin antibody in women with systemic lupus erythematosus. Am J Epidemiol 1993; 138: 1057-69.

[78] Khamashata M, Gil M, Pascual D. Antiphospholipid antibodies in SLE. Clinical association. Clin Exp Rheumatol 1988; 6: 205A.

[79] Kutteh WH, Ermel LD. A clinical trial for the treatment of antiphospholipid antibody-associated recurrent pregnancy loss with lower dose heparin and aspirin. Am J Reprod Immunol 1996; 35 (4): 402-7.

[80] Rai R, Cohen H, Dave M, Regan L. Randomised controlled trial of aspirin and aspirin plus heparin in pregnant women with recurrent miscarriage associated with phospholipid antibodies (or antiphospholipid antibodies). BMJ 1997; 314 (7076): 253-7.

[81] Erkan D, Patel S, Nuzzo M, et al. Management of the controversial aspects of the antiphospholipid syndrome pregnancies: a guide for clinicians and researchers. Rheumatology (Oxford) 2008; 47 (Suppl 3): iii23-7.

[82] Petri M, Howard D, Repke J, Goldman DW. The Hopkins Lupus Pregnancy Center: 1987-1991 update. Am J Reprod Immunol 1992; 28: 188-91.

[83] Johnson MJ, Petri M, Witter FR, Repke JT. Evaluation of preterm delivery in a systemic lupus erythematosus pregnancy clinic. Obstet Gynecol 1995; 86: 396-9.
[84] Laskin CA, Bombardier C, Hannah ME, et al. Prednisone and aspirin in women with autoantibodies and unexplained recurrent fetal loss. N Engl J Med 1997; 337: 148-53.

[85] Cowchock FS, Reece EA, Balaban D, Branch DW, Plouffe L. Repeated fetal losses associated with antiphospholipid antibodies: a collaborative randomized trial comparing prednisone with low-dose heparin treatment. Am J Obstet Gynecol 1992; 166: 1318-23.

[86] Silver RK, MacGregor SN, Sholl JS, Hobart JM, Neerhof MG, Ragin A. Comparative trial of prednisone plus aspirin versus aspirin alone in the treatment of anticardiolipin antibody-positive obstetric patients. Am J Obstet Gynecol 1993; 169 (6): 1411-7.

[87] Lockshin MD. Lupus pregnancies and neonatal lupus. Springer Semin Immunopathol 1994; 16: 247-59.

[88] Jara-Quezada L, Graef A, Lavalle C. Prolactin and gonadal hormones during pregnancy in systemic lupus erythematosus. J Rheumatol 1991; 18: 349-53.

[89] McMurray RW, Allen SH, Braun AL, Rodriguez F, Walker SE. Longstanding hyperprolactinemia associated with systemic lupus erythematosus: possible hormonal stimulation of an autoimmune disease. J Rheumatol 1994; 21: 843-50.

[90] Pauzner R, Urowitz MB, Gladman DD, Gough JM. Prolactin in systemic lupus erythematosus. J Rheumatol 1994; 21: 2064-7.

[91] Buskila D, Lorber M, Neumann L, Flusser D, Shoenfeld Y. No correlation between prolactin levels and clinical activity in patients with systemic lupus erythematosus. J Rheumatol 1996; 23: 629-32.

[92] Ostendorf B, Fischer R, Santen R, Schmitz-Linneweber B, Specker C, Schneider M. Hyperprolactinemia in systemic lupus erythematosus? Scand J Rheumatol 1996, 25: 97-102.

[93] Mok CC, Lau CS, Tam SC. Prolactin profile in a cohort of Chinese systemic lupus erythematosus patients. Br J Rheumatol 1997; 36: 986-9.

[94] Leaños-Miranda A, Cárdenas-Mondragón G. Serum free prolactin concentrations in patients with systemic lupus erythematosus are associated with lupus activity. Rheumatology (Oxford) 2006; 45: 97-101.

[95] Sugiura K, Muro Y, Watanabe A, Tomita Y. A case of systemic lupus erythematosus: continued association of circulating prolactin levels with disease activity over a 4-year follow-up period. Mod Rheumatol 2005; 15 (3): 220-2.

[96] Mok CC, Wong RW, Lau CS. Exacerbation of systemic lupus erythematosus by breast feeding. Lupus 1998; 7: 569-70.

[97] Weetman AP, Walport MJ. The association of autoimmune thyroiditis with systemic lupus erythematosus. Br J Rheumatol 1987; 26: 359-61.

[98] Pyne D, Isenberg DA. Autoimmune thyroid disease in systemic lupus erythematosus. Ann Rheum Dis 2002; 61: 70-2.

[99] Mader R, Mishail S, Adawi M, Lavi I, Luboshitzky R. Thyroid dysfunction in patients with systemic lupus erythematosus (SLE): relation to disease activity. Clin Rheumatol 2007; 26 (11): 1891-4. 